\title{
KESESUAIAN KAWASAN BUDI DAYA RUMPUT LAUT DI TELUK SALEH, KABUPATEN SUMBAWA, NUSA TENGGARA BARAT
}

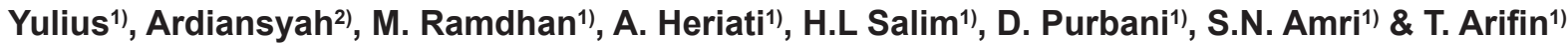 \\ 1) Peneliti pada Pusat Penelitian dan Pengembangan Sumber Daya Laut dan Pesisir, \\ Badan Penelitian dan Pengembangan Kelautan dan Perikanan-KKP \\ 2) Asisten Dosen Jurusan Geografi FMIPA, Universitas Indonesia
}

Diterima tanggal: 27 Nopember 2015; Diterima setelah perbaikan: 29 Desember 2015; Disetujui terbit tanggal 15 Januari 2016

\begin{abstract}
ABSTRAK
Rumput laut merupakan salah satu komoditas sumber daya pesisir dan laut yang memilki nilai ekonomis yang tinggi. Kabupaten Sumbawa memiliki potensi kawasan yang sangat menunjang untuk budi daya rumput laut dengan luas perairan pesisir $\pm 3.831,72 \mathrm{Km}^{2}$. Masyarakat pesisir di sekitar Teluk Saleh melakukan usaha budi daya rumput laut jenis Eucheuma Cottonii. Penelitian ini bertujuan untuk menentukan kesesuaian kawasan untuk budi daya rumput laut menggunakan SIG. Metode yang digunakan dalam penelitian ini adalah metode analisis spasial (keruangan) dan analisa tabular terhadap kesesuaian kawasan dalam SIG. Hasil analisis spasial dan tabular terhadap kesesuaian kawasan untuk budi daya rumput laut berhasil ditentukan kawasan yang sesuai untuk budi daya rumput laut, menunjukkan bahwa lokasi yang sesuai adalah di perairan Kecamatan Plampang dengan luas sekitar 36.061,17 hektar atau 60,34 \% dari luas total wilayah kawasan pengembangan.
\end{abstract}

Kata kunci: Sistem Informasi Geografis (SIG), budi daya rumput laut,Teluk Saleh, Kabupaten Sumbawa

\section{ABSTRACT}

Seaweed is one of the coastal and marine resources commodities which have a high economic value. Sumbawa Regency has a potential area in supporting seaweed cultivation within its total coastal area about $\pm 3831.72 \mathrm{~km}^{2}$. Coastal communities on Saleh Bay farm the Eucheuma Cottonii seaweed. This study aims to determine the suitability of seaweed cultivation area using GIS. The methods used in this research are spatial analysis methods and tabular analysis of area suitability by GIS tools. The results show that Plampang district waters are appropriate as a seaweed cultivation with an area of 36,061.17 hectares or about $60.34 \%$ of total development area.

Keywords: Geographic Information System (GIS), seaweed cultivation, Saleh Bay, Sumbawa Regency

\section{PENDAHULUAN}

Rumput laut merupakan salah satu komoditas sumber daya laut yang memilki nilai ekonomis yang tinggi, mudah dibudidayakan serta biaya produksi yang rendah. Kebutuhan rumput laut diperkirakan terus meningkat seiring dengan meningkatnya kebutuhan untuk konsumsi langsung maupun industri makanan, farmasi dan kosmetik (Kordi, 2010).

Kabupaten Sumbawa memiliki letak georafis $116^{\circ} 42^{\circ} 00^{\prime \prime}-118^{\circ} 22^{\prime} 00^{\prime \prime}$ BT dan $08^{\circ} 08^{\circ} 00^{\prime \prime}-09^{\circ} 07^{\prime} 00^{\prime \prime}$ LS dan memiliki luas wilayah $10.475,70 \mathrm{Km}^{2}(21,20 \%$ NTB) dengan luas daratan $6.643,98 \mathrm{Km}^{2}$ (32,96\% dari daratan NTB), serta dengan luas perairan pesisir dan lautan $3.831,72 \mathrm{Km}^{2}(13,14 \%$ dari perairan NTB) sehingga sangat berpeluang dalam mengembangkan potensi pesisir dan lautan untuk berbagai kegiatan perikanan. Budidaya rumput laut salah satu kegiatan perikanan yang telah dikembangkan dalam rangka memanfaaatkan potensi perairan dan lautan yang telah ada di Kabupaten Sumbawa (Anonim, 2013).

Kegiatan usaha budi daya rumput laut di Kabupaten Sumbawa merupakan jenis usaha budi daya yang cukup berkembang dengan baik, mengingat luas areal yang dapat dimanfaatkan cukup besar yaitu $\pm 58.784,39$ ha. Sampai dengan tahun 2009 pemanfaatan potensi lahan (areal perairan) untuk usaha budi daya rumput laut di Kabupaten Sumbawa sekitar $5.650 \mathrm{Ha}$ dengan total produksi sebesar 27.056 ton (basah)(Anonim, 2013). Pada 2014 Dinas Kelautan dan Perikanan Kabupaten Sumbawa memilki target untuk produksi rumput laut sebesar 359.924 ton, untuk mencapai target yang diinginkan, pemerintah Sumbawa harus meningkatkan wilayah pengembangan rumput laut di daerah-daerah potensial. Lokasi usaha budi daya rumput laut tersebar pada 7 kecamatan yaitu :1) Kecamatan Alas Barat, 2) Kecamatan Lab. Badas, 3) Kecamatan Moyo Hilir, 4) Kecamatan Lape, 5) Kecamatan Maronge, 6) Kecamatan Plampang, 7) Kecamatan Tarano.

Perairan Teluk Saleh memiliki sumber daya alam pesisir dan laut yang beraneka ragam, sehingga untuk masa yang akan datang merupakan sumber ekonomi baru bagi pertumbuhan pembangunan di propinsi NTB (Radjawane, 2006). Teluk Saleh merupakan salah satu sentra pengembangan budi daya rumput laut yang ada di Kabupaten Sumbawa. Masyarakat pesisir di sekitar Teluk Saleh melakukan usaha budi daya rumput laut jenis Eucheuma Cottonii dengan jumlah biomassa 
sekitar 10 ton $\mathrm{Km}^{2}$ dan nilai $\mathrm{P} / \mathrm{B}$ ratio 15,34 tahun (Anonim, 2004).

Pada pengembangan rumput laut, kelayakan lokasi perairan merupakan faktor utama dalam menentukan keberhasilan rumput laut. Hal ini dikarenakan besarnya pengaruh faktor fisika (suhu, kecepatan arus, kecerahan) dan kimia $(\mathrm{pH}$, salinitas, $\mathrm{DO}$, Nutrien) dalam pertumbuhan rumput laut (Puja et al., 2001).

Menurut Puja et al. (2001) salah satu kendala pengembangan budi daya rumput laut pada suatu perairan adalah belum tersedianya data dan informasi yang akurat tentang luasan lahan dan tingkat kelayakan lokasi untuk pengembang budi daya rumput laut. Padahal berhasil tidaknya kegiatan budi daya rumput laut sangat erat kaitannya dengan ketetapan dalam pemilihan dan penentuan lokasi yang tepat. Faktor oseanografi memegang peranan penting dalam prefensi lingkungan selain, topografi serta letak pulau tempat penanaman rumput laut (Barsanti \& Paolo
Gualtiari, 2006).

Bertolak dari hal tersebut maka penelitian ini dilakukan dengan menggunakan pendekatan kesesuaian kawasan dalam Sistem Informasi Geografis (SIG). Penelitian ini bertujuan untuk menentukan kesesuaian kawasan untuk budi daya rumput laut melalui aplikasi SIG.

\section{METODE PENELITIAN}

\section{Waktu dan Tempat Penelitian}

Penelitian ini dilaksanakan di Kawasan Teluk Saleh yang meliputi; Desa Labuan Sangoro Kecamatan Maronge, Desa Labuan Aji Kecamatan Tarano, dan Desa Teluk Santong Kecamatan Plampang, Kabupaten Sumbawa, Provinsi Nusa Tenggara Barat dengan batas koordinat (8॰32'33,039" LS - 8०44'40,15" LS) dan 117'42'21,03" BT - 118'3'20,98” BT)(Gambar 1). Penelitian dilaksanakan pada April 2014.

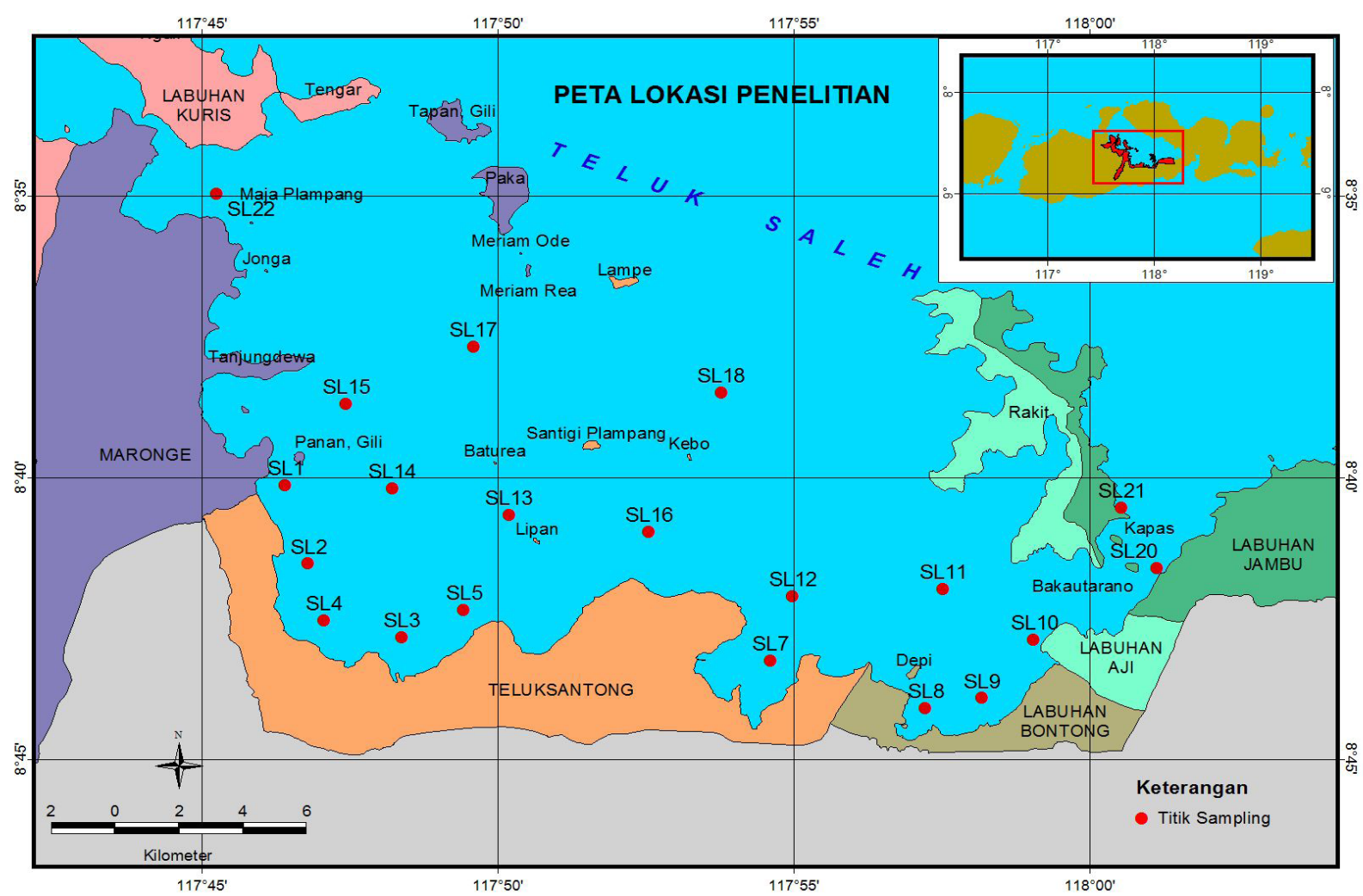

Gambar 1. Peta Lokasi Penelitian. 


\section{Bahan dan Alat Penelitian}

Bahan dan alat penelitian yang digunakan yaitu; peta kedalaman/batimetri laut Dishidros TNI-AL lembar peta Teluk Saleh nomor peta 267 tahun 2005 untuk orientasi di lapangan, multi parameter untuk mengukur suhu, salinitas, DO, pH, flouting droudge untuk mengukur kecepatan arus, sedimen grab untuk mengambil sedimen dasar perairan, secchi disk untuk mengukur kecerahan, wave pole untuk mengukur tinggi gelombang, botol poliethilen untuk tempat sampel air, GPS untuk mendapatkan posisi geografis, kamera digital untuk pemotretan kondisi eksisting dan alat tulis.

\section{Pengumpulan Data}

Data yang digunakan meliputi data sekunder dan data primer. Data primer diperoleh dengan cara melakukan survei dan observasi langsung di lapangan (Tabel 1). Data sekunder diperoleh dari Bappeda Kabupaten Sumbawa, Dinas Tata Ruang Kabupaten Sumbawa, Dinas Kelautan dan Perikanan (DKP) Kabupaten Sumbawa, Badan Pusat Statistik (BPS) Kabupaten Sumbawa, dan Badan Informasi Spasial/ Bakosurtanal (Tabel 2). Dari data sekunder banyak diperoleh gambaran kondisi sosial, ekonomi, budaya, dan fisik yang terdapat di Teluk Saleh secara menyeluruh.

\section{Analisis Data}

Analisis data dilakukan dalam dua tahap yaitu:

\section{A. Analisis Kesesuaian Kawasan (Spasial)}

Analisis kesesuaian kawasan dilakukan dengan Tabel 1. menggunakan Sistem Informasi Geografi (SIG), yaitu sistem informasi spasial berbasis komputer dengan melibatkan perangkat lunak Arc GIS 9.3. Pada analisis ini prinsipnya berupa basis data dari data primer maupun data sekunder dengan data aktual pada 2014 dapat dirumuskan berdasarkan parameter yaitu :

$$
\begin{array}{ll}
\text { a. } & \text { Parameter Fisika } \\
& \text { - suhu, } \\
& \text { - kecepatan arus, } \\
& \text { - dasar perairan, } \\
\text { - kecerahan dan } \\
\text { - tinggi gelombang }
\end{array}
$$

b. Parameter Kimia

- salinitas,

- $\mathrm{pH}$,

- DO,

- nitrat dan

- fosfat

Masing-masing komponen keruangan dijadikan peta tematik dengan skala 1:50.000, kemudian dioverlay-kan untuk mendapatkan peta komposit (peta hasil analisis dengan cara overlay antara seluruh tema peta dalam penentuan kawasan budi daya rumput laut yang sesuai dengan kriteria yang telah ditetapkan seperti terlihat pada Gambar 2.

\section{B. Analisis Tabular}

Menurut Suwargana et al. (2006) kelas

\begin{tabular}{|c|c|c|c|c|}
\hline No & Jenis Data & Teknik Pengumpulan & Alat yang digunakan & $\begin{array}{l}\text { Lokasi Pengumpulan } \\
\text { Data }\end{array}$ \\
\hline 1. & Data Suhu Perairan $\left({ }^{\circ} \mathrm{C}\right)$ & Pengukuran & $\begin{array}{l}\text { Multi parameter untuk } \\
\text { mengukur suhu }\end{array}$ & $\begin{array}{l}\text { Perairan pesisir selatan } \\
\text { Teluk Saleh Kab. }\end{array}$ \\
\hline 2. & Data Salinitas Perairan (\%o ) & Pengukuran & $\begin{array}{l}\text { Multi parameter / } \\
\text { Refraktometer }\end{array}$ & $\begin{array}{l}\text { Sumbawa (Kec. Maronge } \\
\text { Desa Lab. Sangoro }\end{array}$ \\
\hline 3. & Data pH Perairan & Pengukuran & $\begin{array}{l}\text { Multi parameter / } \\
\text { pH Meter }\end{array}$ & $\begin{array}{l}\text { Kec. Tarano - Desa Lab } \\
\text { Aji dan Kec Plampang - }\end{array}$ \\
\hline 4. & Data Kecepatan Arus (cm/detik) & Pengukuran & $\begin{array}{l}\text { Flouting droudge untuk } \\
\text { mengukur kecepatan arus }\end{array}$ & Desa Teluk Santong \\
\hline 5. & Data Dasar Perairan (m) & Identifikasi & Sedimen Grab & \\
\hline 6. & Data kecerahan perairan (\%) & Pengukuran & $\begin{array}{l}\text { Secchi disk untuk menguku } \\
\text { kecerahan perairan }\end{array}$ & \\
\hline 7. & Data Dissolved Oxygen/DO (mg/L) & Pengukuran & Multi parameter /DO meter & \\
\hline 8. & Data Nitrat $(\mathrm{mg} / \mathrm{L})$ & Pengukuran & Poliethilen & \\
\hline 9. & Data Fosfat (mg/L) & Pengukuran & Poliethilen & \\
\hline 10 & Data Tinggi Gelombang (m) & Pengukuran & Wave Pole & \\
\hline
\end{tabular}
kesesuaian kawasan untuk budi daya rumput laut terbagi kedalam 3 (tiga) kelas, yaitu:

1. Kelas S1 (Sesuai) : Daerah ini tidak mempunyai faktor pembatas yang berarti untuk suatu penggunaan secara lestari (total skor: $>35$ ) 
Tabel 2. Pengumpulan data sekunder

\begin{tabular}{|c|c|c|c|c|}
\hline No & Jenis Data & Teknik Pengumpulan & Skala/ Resolusi & Sumber \\
\hline & Data Biofisik dan Oseanografi & & & \\
\hline 1. & $\begin{array}{l}\text { Peta Kedalaman/Batimetri Laut, } \\
\text { Teluk Saleh nomor peta } 267 \text { (2005) }\end{array}$ & $\begin{array}{l}\text { Inventarisasi profil dasar } \\
\text { daerah penelitian }\end{array}$ & $1: 50.000$ & Dishidros TNI-AL \\
\hline 2. & Peta Rupa Bumi Indonesia (1992) & & $1: 50.000$ & BIG/Bakosurtanal \\
\hline 3. & $\begin{array}{l}\text { Peta Geologi Lembar Sumbawa, } \\
\text { Nusa tenggara (2012) }\end{array}$ & & $1: 250.000$ & $\begin{array}{l}\text { Puslitbang Geologi } \\
\text { (P3G) - ESDM }\end{array}$ \\
\hline \multirow[t]{3}{*}{4.} & Dokumen Teknis Rencana Tata Ruang & & & Dinas Tata Ruang \\
\hline & Wilayah (RTRW) Kabupaten Sumbawa & & & Kabupaten Sumbawa \\
\hline & $2011-2031$ & & & BAPPEDA Sumbawa \\
\hline \multirow[t]{2}{*}{5.} & Rencana Induk Kawasan Minapolitan & & & Dinas Kelautan dan \\
\hline & Perikanan Kabupaten Sumbawa & & & Perikanan (DKP) \\
\hline \multirow[t]{4}{*}{6.} & Laporan Akhir dari kegiatan Penyusunan & & & Kabupaten Sumbawa \\
\hline & Dokumen Awal Rencana Zonasi Wilayah & & & \\
\hline & Pesisir dan Pulau-Pulau Kecil Kabupaten & & & \\
\hline & Sumbawa, & & & \\
\hline \multirow[t]{2}{*}{7.} & Laporan Tahunan Dinas Kelautan dan & & & \\
\hline & $\begin{array}{l}\text { Perikanan (DKP) Kabupaten Sumbawa } \\
\text { tahun } 2012\end{array}$ & & & \\
\hline \multirow[t]{2}{*}{8.} & Laporan Akhir Penyusunan Rencana & & & \\
\hline & Detail Tata Ruang Kawasan Teluk Saleh & & & \\
\hline \multirow[t]{2}{*}{9.} & Laporan Akhir Profil Perikanan Budidaya & & & \\
\hline & Kabupaten Sumbawa & & & \\
\hline 10. & $\begin{array}{l}\text { Kabupaten Sumbawa Dalam Angka Tahun } \\
2013\end{array}$ & & & $\begin{array}{l}\text { Badan Pusat Statistik } \\
\text { (BPS) Kab. Sumbawa }\end{array}$ \\
\hline \multirow[t]{2}{*}{11.} & Hasil survei kawasan budidaya Teluk & & & BIG / Bakosurtanal \\
\hline & Saleh tahun 2009 & & & \\
\hline
\end{tabular}

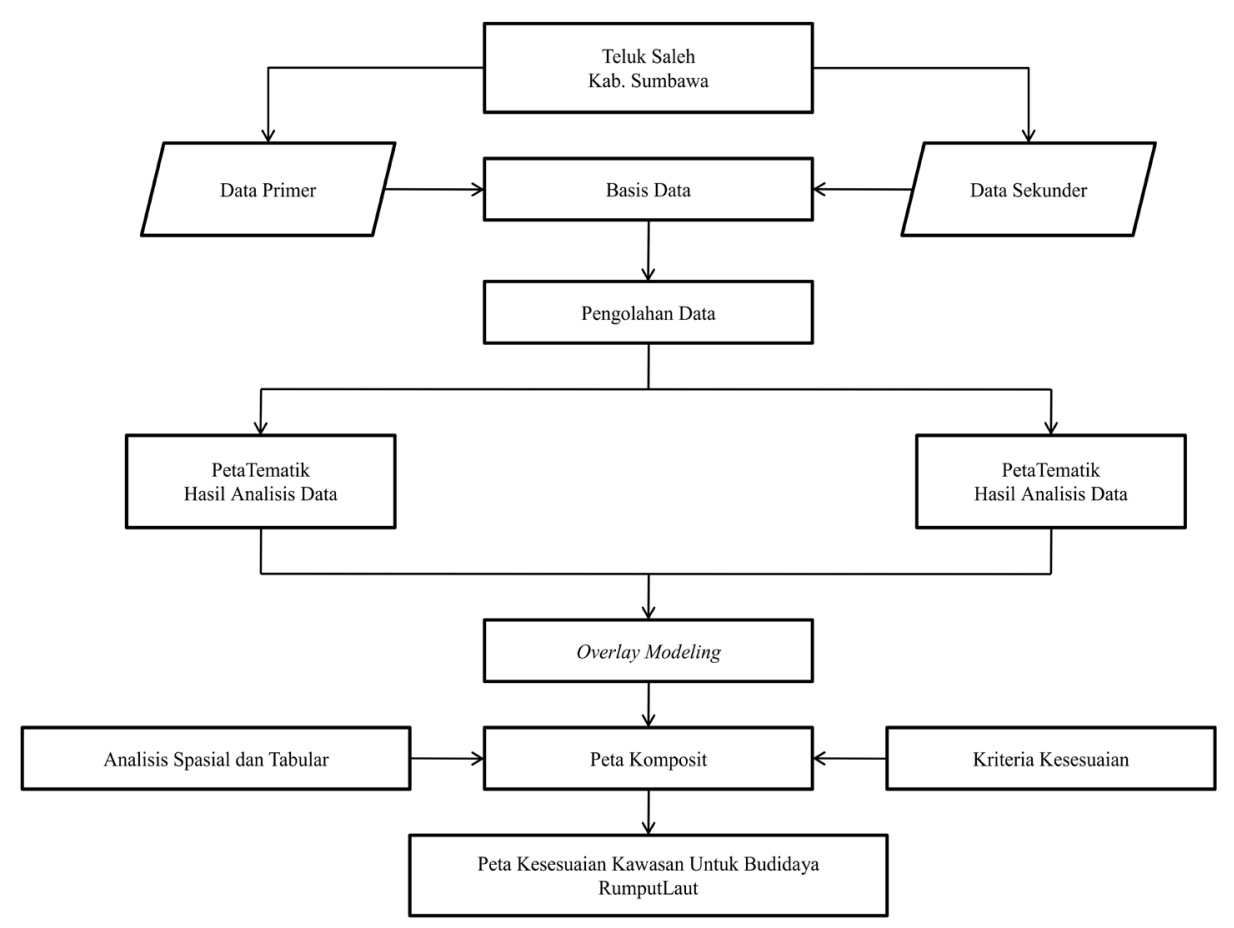

Gambar 2. Diagram Analisis Integrasi SIG Kesesuaian Kawasan Untuk Budi daya Rumput Laut 
2. Kelas S2 (Sesuai Bersyarat) : Daerah ini mempunyai faktor pembatas yang dapat mengurangi tingkat produksi atau keuntungan yang diperoleh (total skor: 25 - 35)

3. Kelas N (Tidak Sesuai) : Daerah ini sarankan untuk tidak digunakan, karena faktor pembatasnya bersifat permanen (total skor: <25)

Penentuan kesesuaian lahan untuk budidaya rumput laut dilakukan dengan metode pembobotan. Parameter-parameter utama kesesuaian yang diperlukan untuk budi daya rumput laut disajikan dalam Tabel 3.

\section{HASIL DAN PEMBAHASAN}

\section{Peta Tematik dalam penentuan kawasan budi daya rumput laut}

Peta tematik hasil analisis dalam penentuan kesesuaian kawasan budi daya rumput laut dilakukan dengan menggunakan Sistem Informasi Geografi (SIG) yang masing-masing komponen keruangan dijadikan peta tematik dengan skala 1:50.000. Peta tematik berdasarkan parameter fisika dan kimia seperti terlihat pada Gambar 3.

Tabel 3.

Matriks Kesesuaian Kawasan Untuk Budidaya Rumput Laut

\begin{tabular}{|c|c|c|c|c|c|}
\hline No & Parameter & Kisaran & Nilai (A) & Bobot (B) & Skor(AxB) \\
\hline \multirow[t]{3}{*}{1.} & Suhu $\left({ }^{\circ} \mathrm{C}\right)$ & $27-30$ & 3 & 1 & 3 \\
\hline & & $25-<27$ atau $>30-32$ & 2 & & 2 \\
\hline & & $<25$ atau $>32$ & 1 & & 1 \\
\hline \multirow[t]{3}{*}{2.} & Salinitas (\%o) & $29-33$ & 3 & 1 & 3 \\
\hline & & $25-<29$ atau $>33-37$ & 2 & & 2 \\
\hline & & $<25$ atau $>37$ & 1 & & 1 \\
\hline \multirow[t]{3}{*}{3.} & $\mathrm{pH}$ & $7-8,5$ & 3 & 1 & 3 \\
\hline & & $6,5-<7$ atau $>8,5-9,5$ & 2 & & 2 \\
\hline & & $<6,5$ atau $>9,5$ & 1 & & 1 \\
\hline \multirow[t]{3}{*}{4.} & Kecepatan Arus & $20-40$ & 3 & 2 & 6 \\
\hline & (cm/detik) & $10-20$ atau $40-50$ & 2 & & 4 \\
\hline & & $<10$ atau $>50$ & 1 & & 2 \\
\hline \multirow[t]{3}{*}{5.} & Dasar Perairan & Pasir & 3 & 1 & 3 \\
\hline & (m) & Pasir Berlumpur & 2 & & 2 \\
\hline & & Lumpur & 1 & & 1 \\
\hline \multirow[t]{3}{*}{6.} & Kecerahan (m) & $>5$ & 3 & 2 & 6 \\
\hline & & $3-4$ & 2 & & 4 \\
\hline & & $<3$ & 1 & & 2 \\
\hline \multirow[t]{3}{*}{7.} & Dissolved Oxygen/DO & $>4$ & 3 & 2 & 6 \\
\hline & $(\mathrm{mg} / \mathrm{L})$ & $2-4$ & 2 & & 4 \\
\hline & & $<2$ & 1 & & 2 \\
\hline \multirow[t]{3}{*}{8.} & Nitrat (mg/L) & $0,9-3,5$ & 3 & 2 & 6 \\
\hline & & $0,01-0,08$ atau $3,6-4,4$ & 2 & & 4 \\
\hline & & $<0,1$ atau $>4,5$ & 1 & & 2 \\
\hline \multirow[t]{3}{*}{9.} & Fosfat (mg/L) & $0,051-1$ & 3 & 1 & 3 \\
\hline & & $0,021-0,05$ & 2 & & 2 \\
\hline & & $<0,021$ atau $>1$ & 1 & & 1 \\
\hline \multirow[t]{3}{*}{10.} & Tinggi Gelombang (m) & $0,2-0,3$ & 3 & 2 & 6 \\
\hline & & $0,1-0,19$ atau $0,3-0,4$ & 2 & & 4 \\
\hline & & $<0,1$ atau $>0,4$ & 1 & & 2 \\
\hline
\end{tabular}

Keterangan:

Angka Penilaian yaitu; 3 : Baik, 2 : Sedang dan 1 : Kurang

Bobot berdasarkan pertimbangan pengaruh variabel dominan

Sumber: Hasil modifikasi dari Aslan. (1988); Utojo et al., (2007); Ariyati, (2007); Kangkan, (2006); Cornelia et al. (2005) 


\section{Parameter Fisika}
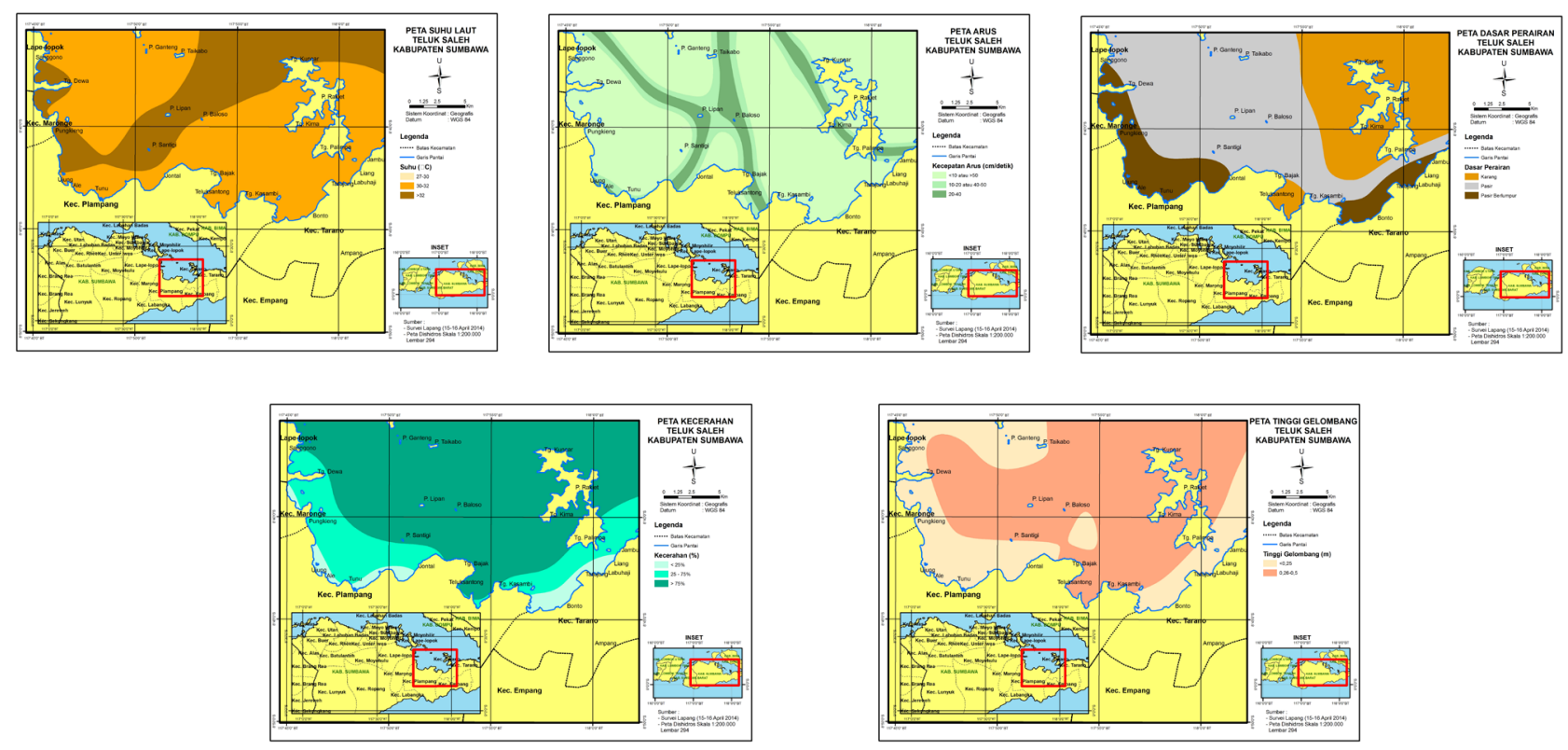

\section{Parameter Kimia}
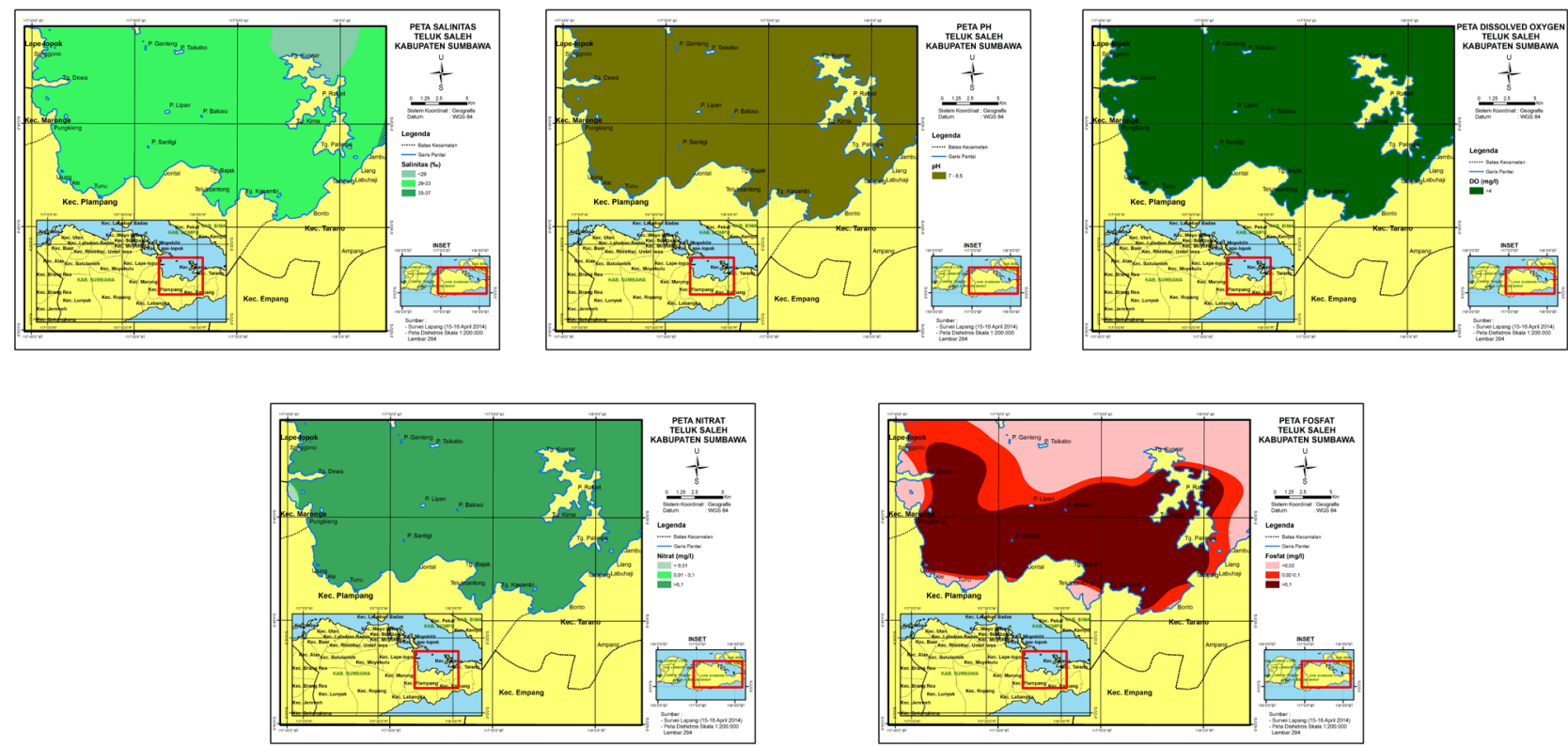

Gambar 3. Peta Tematik dalam penentuan kawasan Budidaya Rumput Laut Parameter (Parameter Fisika); untuk posisi lintang dan bujur dapat dilihat pada Gambar 1.

Matrik hasil analisis tabular penentuan kawasan budi daya rumput laut

Hasil kesesuaian kawasan untuk budi daya rumput laut dilakukan dengan metode pembobotan seperti terlihat pada lampiran Tabel 1. Kesesuaian kawasan yang dihasilkan dalam penelitian ini merupakan kesesuaian aktual (actual suitability), yang tingkat kesesuaiannya hanya didasarkan pada data yang tersedia dan belum mempertimbangkan asumsi atau usaha perbaikan serta tingkat pengelolaan yang dapat dilakukan untuk mengatasi berbagai kendala fisik atau faktor-faktor penghambat yang ada sehingga dapat mempengaruhi kelas kesesuaian budi daya rumput laut. 
Analisis Spasial Kesesuaian Kawasan Budi daya Rumput Laut

Berdasarkan hasil analisis kesesuaian kawasan secara spasial, kawasan budi daya rumput laut pada daerah penelitian dapat dibagi menjadi 2 (dua) kelas, yaitu: (1) kelas kesesuaian lahan dengan kategori S1 (Sesuai) dengan area seluas 36.061,17 hektar $(60,34 \%)$, dan (2) kelas kesesuaian lahan dengan kategori S2 (Sesuai Bersyarat) dengan area seluas 23.700,43 hektar (39,66\%), seperti ditunjukkan dalam Tabel 4. Peta sebaran secara spasial kelas kesesuaian untuk kawasan budi daya rumput laut dapat dilihat pada Gambar 4.

Kawasan budi daya rumput laut dengan kriteria sesuai (S1), yaitu hampir sebagian besar parameter fisika dan kimia yang dikaji pada kawasan tersebut sesuai untuk budi daya rumput laut. Berdasarkan
Tabel 4, serta penyajian secara spasial pada Gambar 4 diketahui bahwa kawasan yang sesuai merupakan daerah yang berada pada sepanjang perairan pesisir Kecamatan Plampang dengan luas sekitar 36.061,17 hektar atau $60,34 \%$ dari luas total wilayah kawasan pengembangan.

Pada kawasan tersebut memiliki nilai parameter fosfat $\left(\mathrm{PO}_{4}{ }^{3-}\right)$ tinggi, sumber fosfat di perairan pesisir adalah sungai, karena sungai membawa hanyutan sampah maupun sumber fosfat dari darat, selain itu dapat pula berasal dari hutan mangrove dan lamun melalui dekomposisi serasah (Connel et al.,1995 dalam Ahmad, 2004). Konsentrasi fosfat tertinggi di lokasi penelitian terdapat di stasiun SL2 dengan nilai konsentrasi $0,65 \mathrm{mg} / \mathrm{l}$, sedangkan konsentrasi terendah terdapat di stasiun SL20 dengan nilai konsentrasi 0,03 $\mathrm{mg} / \mathrm{l}$. Selain itu nilai parameter nitrat $\mathrm{NO}_{3}^{-}$juga tinggi, nitrat merupakan nutrien utama bagi pertumbuhan

Tabel 4.

Luas Kawasan Kesesuaian Lahan Untuk Kawasan Budi daya Rumput Laut

\begin{tabular}{|c|c|c|c|}
\hline & Kelas Budi daya Rumput Laut & Luas (ha) & Persentase (\%) \\
\hline 1 & Sesuai (S1) & $36.061,17$ & 60,34 \\
\hline 2 & Sesuai Bersyarat (S2) & $23.700,43$ & 39,66 \\
\hline & Luas Keseluruhan & \multicolumn{2}{|c|}{$9.761 .50100,00$} \\
\hline
\end{tabular}

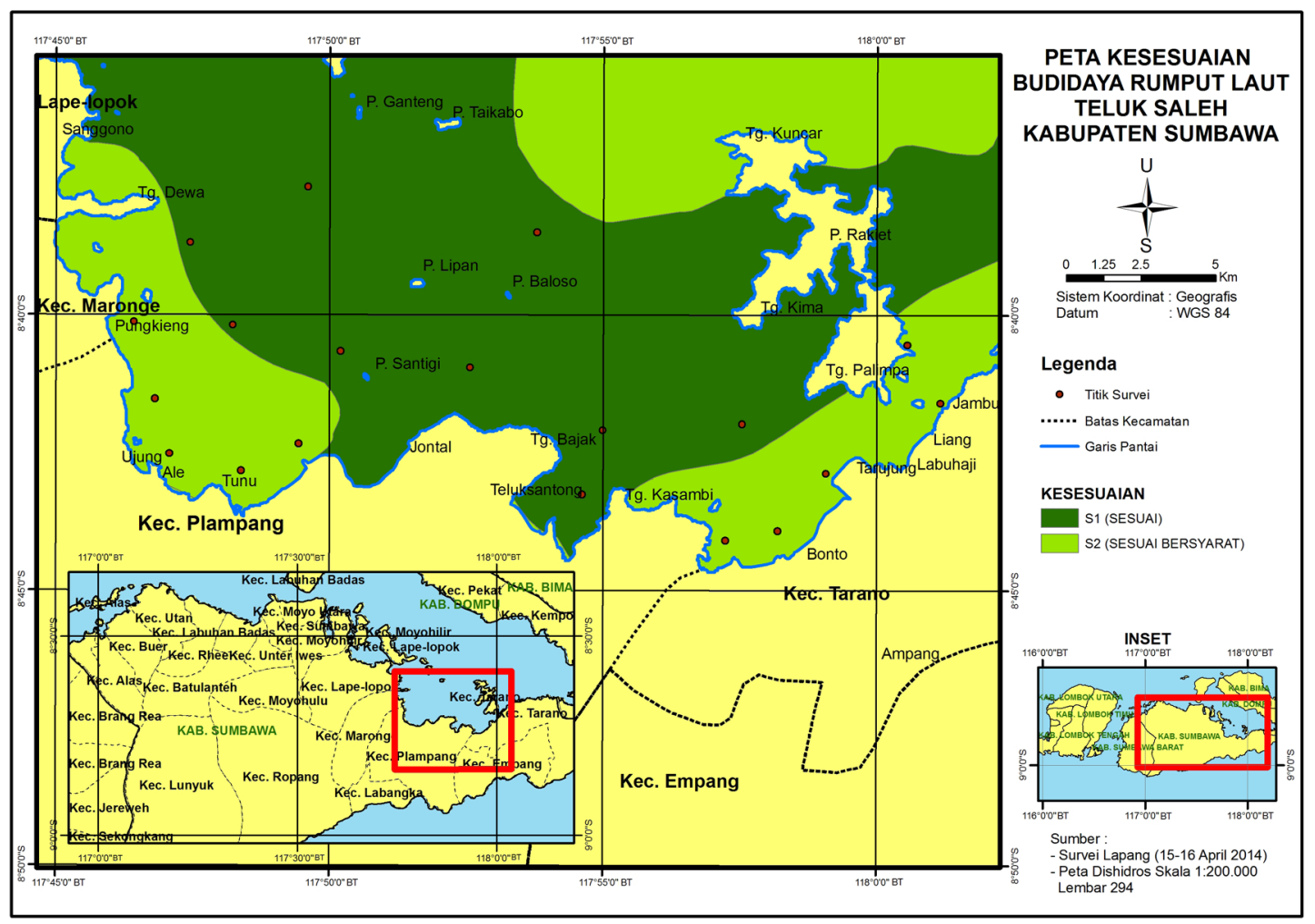

Gambar 4. Peta Kesesuaian Kawasan Untuk Budi daya Rumput Laut. 
tanaman dan alga (Effendi, 2003). Konsentrasi nitrat tertinggi di lokasi penelitian di stasiun SL2 dengan konsentrasi sebesar 4,9 mg/l, sedangkan konsentrasi terendah terdapat di stasiun SL17 dengan nilai konsentrasi $1,1 \mathrm{mg} / \mathrm{l}$.

Hasil pengamatan lapangan jenis rumput laut yang banyak dibudidayakan masyarakat di Teluk Saleh Kabupaten Sumbawa adalah Eucheuma cottonii. Rumput laut jenis ini memiliki kandungan karaginan kappa yang tinggi, berwarna hijau kekuningan, thallusnya berbentuk silinder dan bercabang, permukaan licin dan kenyal seperti terlihat pada Gambar 5. Karaginan sebagai hasil olahan rumput laut dapat diolah menjadi bahan makanan dan minuman, pet-food, bahan baku industry farmasi serta kosmetik (Luhur et al., 2012).

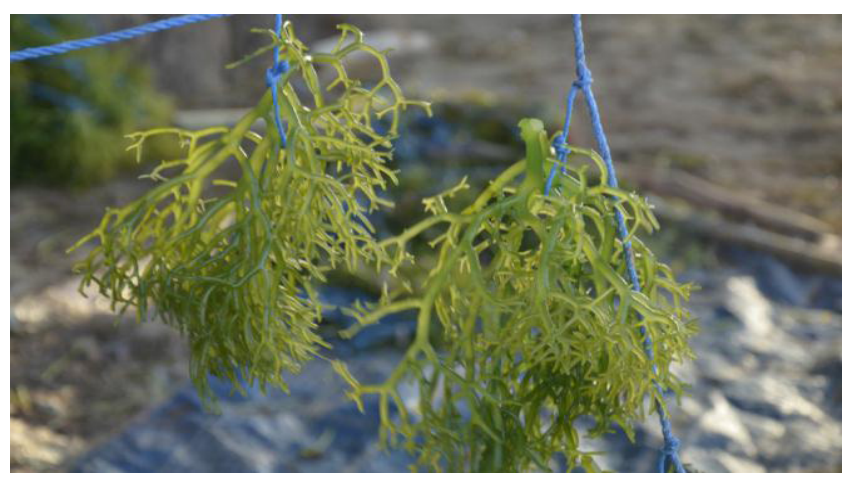

Gambar 5. Rumput laut Eucheuma cottonii.

Lokasi budi daya rumput laut di Teluk Saleh Kabupaten Sumbawa umumnya di sekitar pesisir yang tidak jauh dari lingkungan permukiman. Bahkan di beberapa lokasi jaraknya kurang dari 500 meter dari lokasi pelabuhan dan permukiman. Jarak ini dinilai terlalu dekat dari pelabuhan sehingga potensial mengganggu aktivitas yang ada terutama alur keluar masuk perahu atau kapal dari dan ke pelabuhan (Anonim, 2013).

Teknologi budi daya rumput laut yang banyak dikembangkan di Teluk Saleh adalah metode long line seperti terlihat pada Gambar 6. Teknologi long line yaitu pembudidaya di kolom air (eupotik) dekat permukaan perairan laut dengan menggunakan tali yang dibentangkan dari satu titik ke titik yang lain dengan panjang 25-30 m, dalam bentuk terangkai berbentuk segi empat dengan bantuan pelampung dan jangkar sesuai dengan SNI 7579.3:2010 (Ditjen Perikanan Budi daya 2011 dalam Yulisti 2012). Menurut Luhur et al. (2012) strategi yang digunakan untuk memulai usaha budi daya rumput laut jenis Eucheuma cottonii dengan metode long line adalah membeli tali yang dibutuhkan, patok kayu/jangkar dan pelampung serta bibit. Selain itu strategi pengembangan kompetensi pembudidaya dalam meningkatkan produktivitas dan pendapatan rumput laut dapat dilakukan dengan cara mengefektifkan penyuluh secara partisipatif, memperbesar intensitas penyuluh dengan pendekatan kelompok (Kustiari, 2012).

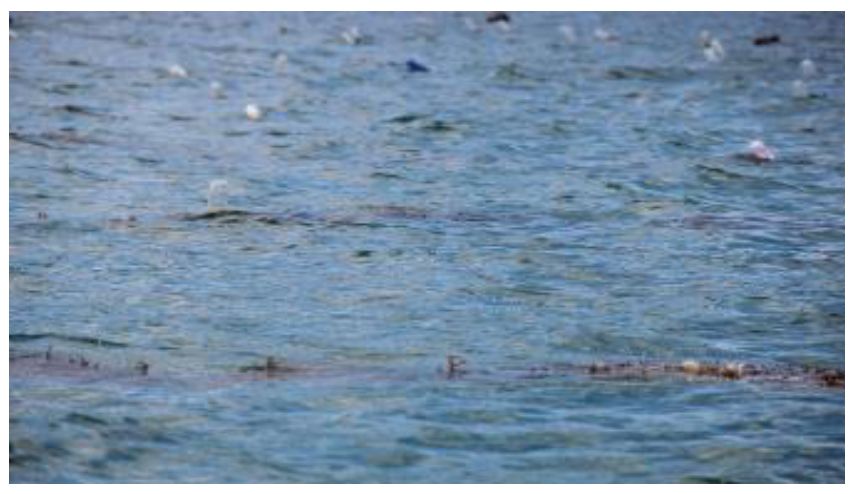

Gambar 6. Budi daya rumput laut metode long line.

Benih rumput laut yang dibudidayakan umumnya berasal dari lokasi sekitar. Ketersediaan bibit rumput laut di Teluk Saleh relatif cukup tersedia dan mudah didapat. Bibit ini umumnya diambil dari hasil budidaya sebelumnya untuk selanjutnya dibudidayakan kembali. Bobot bibit yang digunakan per ikatan berkisar antara 50 sampai 100 gram dengan jarak tanam berkisar antara $20-25 \mathrm{~cm}$.

Kegiatan pemeliharaan rumput laut pada pembudidaya di Teluk Saleh umumnya sekitar 45 hingga 60 hari atau disesuaikan dengan kebutuhan pasar. Cara panen yang banyak dilakukan oleh pembudidaya adalah panen secara keseluruhan dengan cara diangkat langsung seluruh jaring yang ada rumput lautnya dan dimasukkan ke perahu pengangkut. Pemasaran untuk rumput laut di lokasi tidak susah karena sudah ada pembeli yang biasa menampung hasil budi daya dari para pembudidaya walaupun struktur pasarnya monopolis yang dapat berimplikasi terhadap harga yang terbentuk.

\section{KESIMPULAN}

Berdasarkan hasil analisis kesesuaian kawasan dengan aplikasi SIG di di Teluk Saleh Kabupaten Sumbawa, berhasil ditentukan kawasan yang sesuai untuk budi daya rumput laut, menunjukkan bahwa lokasi yang sesuai adalah di sepanjang perairan pesisir Kecamatan Plampang dengan luas sekitar 36.061,17 hektar atau 60,34 \% dari luas total wilayah kawasan pengembangan. Berdasarkan hasil analisis tabular kelas kesesuaian budi daya rumput laut sesuai (S1) dengan nilai skor tertinggi yaitu sebesar 42 berada di stasiun laut (SL) 7 . 


\section{Saran}

Penelitian ini hanya dikonsentrasikan pada bagian selatan Teluk Saleh oleh karena itu diperlukan penelitian lanjutan di bagian utara Teluk Saleh pada kawasan yang belum mempunyai data untuk menghasilkan data pengembangan pesisir untuk pengelolaan Budi daya Rumput Laut di seluruh wilayah Teluk Saleh.

\section{PERSANTUNAN}

Kami ucapkan terima kasih kepada Badan Penelitian dan Pengembangan Kelautan dan Perikanan, KKP atas bantuan dana untuk menyelesaikan penelitian ini. Ucapan terima kasih juga disampaikan Kepada kepala Dinas Kelautan dan Perikanan Kabupaten Sumbawa atas bantuan sarana dan prasarana sehingga penelitian ini dapat terlaksana dengan baik.

\section{DAFTAR PUSTAKA}

Anonim. (2013). Rencana Zonasi Wilayah Pesisir Dan Pulau-Pulau Kecil Kabupaten Sumbawa. Ditjen Pesisir dan Pulau-Pulau Kecil. Direktorat Tata Ruang Laut, Pesisir dan Pulau-Pulau Kecil. Jakarta.

Anonim. (2004). Daya Dukung Kelautan dan Perikanan Selat Sunda, Teluk Tomini, Teluk Saleh dan Teluk Ekas. Badan Riset Kelautan dan Perikanan. Jakarta. $122 \mathrm{hlm}$.

Ahmad, F. (2004). Kesuburan Perairan Kepulauan Tanimbar Utara dan Selatan, Maluku Tenggara Ditinjau dari Kadar Zat Hara Fosfat. Jurnal IImiah Sorihi, III(1) : 61-72.

Ariyati, R. W., L. Sya'rani \& Endang Arini. (2007). Analisis Kesesuaian Perairan Pulau Karimun Jawa dan Pulau Kemujan Sebagai Lahan Budidaya Rumput Laut Menggunakan Sistem Informasi Geografis. UNDIP, Semarang. $45 \mathrm{hlm}$.

Aslan. (1988). Rumput Laut. Penerbit Kanisius, Yogyakarta.

Barsanti \& Paolo Gualtiari. (2006). Algae Anatomy, Biochemistry, and Biotechnology. Taylor \& Francis. New York. USA.

Cornelia, M.I., Suryanto, H. \& Ambarwulan, W. (2005). Prosedur dan Spesifikasi Teknis Analisis Kesesuaian Budidaya Rumput Laut. Pusat Survei Sumberdaya Alam Laut. Bakosurtanal. Cibinong.
Effendi, H. (2003). Telaah Kualitas Air. Penerbit Kanisius, Yogyakarta.

Kangkan, A.L. (2006). Studi Penentuan Lokasi untuk Pengembangan Budidaya Laut Berdasarkan Parameter Fisika, Kimia dan Biologi di Teluk Kupang, Nusa Tenggara Timur. Tesis. UNDIP, Semarang. $102 \mathrm{hlm}$.

Kordi, K.M.G.H. (2010). Kiat Sukses Budidaya Rumput Laut di Laut dan di Tambak. Penerbit ANDI. Yogyakarta.

Kustiari, T., Sumardjo, Selamet, M. \& Tjitropranoto, P. (2012). Pengaruh Efektifitas Penyuluh Terhadap Kompetensi Pembudidaya Rumput Laut Polikultur di Perairan Pantai Utara Pulau Jawa. Jurnal Sosial Ekonomi Kelautan dan Perikanan. $7(1): 79-95$.

Luhur, E.S., Witomo, C.M. \& Firdaus, M. (2012). Analisis Daya Saing Rumput Laut di Indonesia (Studi Kasus: Kabupaten Konawe Selatan, Sulawesi Tenggara). Jurnal Sosial Ekonomi Kelautan dan Perikanan. 7(1) : $55-66$.

Puja, Y., Sudjiharno \& Aditya, TW. (2001). Pemilihan Lokasi Budidaya. Dalam Teknologi Budidaya Rumput Laut, Kappaphycus allvarezii. Departemen Kelautan dan Perikanan, Direktorat Jendral Perikanan Budidaya. Balai Budidaya Laut Lampung. Juknis seri No. 8, hlm 13-17.

Radjawane, I.M. (2006). Sirkulasi Arus Vertikal Di Perairan Teluk Saleh Sumbawa, Nusa Tenggara Barat. Jurnal Segara, Vol 2 (1): 10-15.

Suwargana, N., Sudarsono. \& V. P. Siregar. (2006). Analisis Lahan Tambak Konvensional Melalui Uji Kualitas Lahan dan Produksi dengan Bantuan Penginderaan Jauh dan SIG. Jurnal Penginderaan Jauh dan Pengolahan Data Citra Digital. 3(1) : 1- 13 .

Utojo, Malik. A. T. \& Hasnawi. (2007). Pemetaan Kelayakan Lahan Untuk Pengembangan Budidaya Rumput Laut Di Teluk Sopura, Kabupaten Kolaka Propinsi Sulawesi Tenggara. Jurnal Ilmu Kelautan dan Perikanan Torani. Makassar.

Yulisti, M., Yusuf, L. \& Hikmah. (2012). Kajian Awal Value Chain Rumput Laut Eucheuma Cottonii di Kabupaten Pangkep, Sulawesi Selatan. Jurnal Sosial Ekonomi Kelautan dan Perikanan. 7(1) : $67-77$. 
